\title{
Protective effects of hydrogen gas in a rat model of branch retinal vein occlusion via decreasing VEGF-a expression
}

Pan Long ${ }^{1 \dagger}$, Weiming Yan ${ }^{2 \dagger}$, Mengshan He ${ }^{3}$, Qianli Zhang ${ }^{4}$, Zhe Wang ${ }^{4}$, Manhong Li ${ }^{5}$, Junhui Xue ${ }^{1}$, Tao Chen ${ }^{{ }^{*}}$, Jing $\mathrm{An}^{6^{*}}$ and Zuoming Zhang ${ }^{1 *}$

\begin{abstract}
Background: Oxidative stress (OS) is an essential factor in the pathogenesis of branch retinal vein occlusion (BRVO). Studies have demonstrated the role of hydrogen gas in the regulation of OS. This study was designed to evaluate the efficacy of hydrogen gas on the BRVO rat model.

Methods: Twenty-four BRVO rats were randomly divided into two groups: the hydrogen gas $(H)$ group $\left(42 \% \mathrm{H}_{2}\right.$, $\left.21 \% \mathrm{O}_{2}, 37 \% \mathrm{~N}_{2}\right)$ and the model $(\mathrm{M})$ group $\left(21 \% \mathrm{O}_{2}, 79 \% \mathrm{~N}_{2}\right)$. Rats in the $\mathrm{H}$ group inhaled hydrogen gas for $8 \mathrm{~h}$ every day up to $30 \mathrm{~d}$ post-occlusion. Twelve age-matched healthy rats served as the control (C) group. Retinal function and morphology were detected at 1, 7, 14 and $30 \mathrm{~d}$ post-occlusion. Furthermore, the expression of vascular endothelial growth factor (VEGF-a) was detected by immunofluorescent staining.
\end{abstract}

Results: Full-field electroretinography (ffERG) revealed that the amplitude of the b-wave (dark-adaptation 3.0 response), the amplitude of the OPs2 wave and the light-adapted flicker response in the $\mathrm{H}$ group were all higher than those in the $\mathrm{M}$ group at $7 \mathrm{~d}$ post-occlusion (all $p<0.05$ ). The reopen time of occlusive retinal vessels in the $\mathrm{H}$ group was $2.235 \pm 1.128 \mathrm{~d}$, which was shorter than that in the $\mathrm{M}$ group $(4.234 \pm 2.236 \mathrm{~d}, p<0.05)$. The rats in the $\mathrm{H}$ group had a thinner $\mathrm{PL}+\mathrm{GCL}+\mathrm{NFL}$ and an increased total retina compared with those in the $\mathrm{M}$ group at $3 \mathrm{~d}$ post-occlusion $(p<0.05)$, while the rats in the $\mathrm{H}$ group had a thicker $I N L, I P L+G C L+N F L$ and total retina compared with those at 7, 14 and $30 \mathrm{~d}$ post-occlusion $(p<0.05)$. Moreover, the flow velocity of ear vein blood was increased in the $\mathrm{H}$ group compared with that in the $\mathrm{M}$ group $(p<0.05)$. The expression of VEGF-a in the $\mathrm{H}$ group was dramatically decreased compared with that in the $\mathrm{M}$ group at 1, 7 and $14 \mathrm{~d}$ post-occlusion $(p<0.05)$, while the expression kept in similar level at $30 \mathrm{~d}$ post-occlusion $(p>0.05)$.

Conclusions: Our findings demonstrate that inhalation of hydrogen gas could alleviate retinal oedema, shorten reopen time and improve retinal function, and the potential mechanism might be related to a decrease in VEGF-a expression.

Keywords: Hydrogen gas, Branch retinal vein occlusion, Electroretinography, Vascular endothelial growth factor

\footnotetext{
*Correspondence: baiidtf0506@126.com; anjing@xjtu.edu.cn;

zhangzm@fmmu.edu.cn

${ }^{\dagger}$ Pan Long and Weiming Yan are contributed equally to this work.

${ }^{1}$ Center of Clinical Aerospace Medicine, Fourth Military Medical University,

No.169 Changle West Road, Xi'an 710032, Shaanxi, China

${ }^{6}$ Institute of Neurobiology, School of Basic Medical Sciences, Xi'an Jiaotong

University, No.76 Yanta Weast Road, Xi'an 710061, Shaanxi, China

Full list of author information is available at the end of the article
}

(c) The Author(s). 2019 Open Access This article is distributed under the terms of the Creative Commons Attribution 4.0 International License (http://creativecommons.org/licenses/by/4.0/), which permits unrestricted use, distribution, and

reproduction in any medium, provided you give appropriate credit to the original author(s) and the source, provide a link to the Creative Commons license, and indicate if changes were made. The Creative Commons Public Domain Dedication waiver (http://creativecommons.org/publicdomain/zero/1.0/) applies to the data made available in this article, unless otherwise stated. 


\section{Background}

Retinal vein occlusion (RVO) is mainly classified with central retinal vein occlusion (CRVO) and branch retinal vein occlusion (BRVO) according to the occlusive vein sites. It is well known that a severe sight-threatening ophthalmic vessel disease most commonly affects middle-aged ranging to older people $[1,2]$. Compared with CRVO, BRVO features higher morbidity and a larger therapeutic window of opportunity, which should be optimized with management [3]. Currently, first-line therapeutic methods include glucocorticoid, anti-VEGF, laser photocoagulation, and traditional herb medicines (mostly in eastern countries) [4]. However, those treatment methods cannot meet the needs of some individuals. Specifically, glucocorticoid is convenient but inevitably produces various adverse side effects, such as increased susceptibility to infection, damage to the optic nerve, cataracts, and so on [5-7]. Although adverse events following anti-VEGF therapy are rare, it would be relevant to address these challenges, including frequent visits for injections [8], recurrent macular oedema [9, 10], anti-VEGF non-responders [9], time-dependent effects [11] and high expenses related to the agents [12]. Conventional medicine could not produce satisfactory results because of the blood-retina barrier and the unique structure of the retina. Therefore, it is urgent to explore effective measures against BRVO with evident therapeutic effects and fewer adverse side effects.

Recently, hydrogen gas, as a novel inert gas, has aroused much interest in medical areas. A remarkable achievement is clinical research confirming that inhalation of hydrogen gas could alleviate brain ischaemia/reperfusion (I/R) injury via anti-inflammation and antioxidation [13]. More experimental evidence, including studies on the brain, heart, liver, lung, kidney and eye, has confirmed the beneficial role of the inhalation of hydrogen gas. Furthermore, our laboratory previously applied hydrogen gas in several ophthalmic diseases, including retina injury induced by intense light [14], retinitis pigmentosa induced by methylnitrosourea (MNU) [15], dry eyes and endotoxin-induced uveitis [16], which verified the potential value of hydrogen gas on ophthalmic diseases.

In this study, we proposed the hypothesis that hydrogen gas could be a new therapeutic method for treating BRVO, collected therapeutic evidence of hydrogen gas and explored the relationship with the expression of VEGF- $\alpha$.

\section{Methods}

\section{Animals}

Forty-two adult male Sprague-Dawley (SD) rats (6-8 weeks, $180-220 \mathrm{~g}$ ) were obtained from the Laboratory Animal Center of the Fourth Military Medical University (license No. 2014270138S). The rats were raised and tested under the condition with food and water free intake and maintained room temperature $23^{\circ} \mathrm{C} \pm 3{ }^{\circ} \mathrm{C}$, humidity $45-65 \%$, and $12 \mathrm{~h}$ light $/ 12 \mathrm{~h}$ dark cycle. In this study, the experimental protocols were approved by the ethical committee of the Animal Care and Experimental Committee of the Fourth Military Medical University. All experiments were in accordance with the Association for Research in Vision and Ophthalmology (ARVO) statements for ophthalmic research animal use. Rats were euthanized with lethal sodium pentobarbital (3\%, $10 \mathrm{ml} / \mathrm{kg}$ ) (Sigma, St Louis, MO, USA) at each detection point.

\section{BRVO model}

Thirty rats were anaesthetized by intraperitoneal injection (IP) with $1 \%$ sodium pentobarbital $(3 \mathrm{~mL} / \mathrm{kg})$ and sumianxin II $(50 \mu \mathrm{L}$ each rat) (Jilin Shengda Animal Pharmaceutical Co., Ltd., Jilin, China), and $50 \mathrm{mg} / \mathrm{mL}$ Rose Bengal (Chengdu aikeda reagent co. Ltd., Sichuan, China) was injected into the rat tail vein 1 min before laser applied. Additionally, the right eye was dilated with 0.5\% tropicamide (Shenyang Xingji Co., Ltd., Liaoning, China). Then, bifurcation of the retinal vein secondary vasculature was found using a Micron IV Retinal Imaging Microscope (Lumenis, Inc., USA), and 50 laser spots were applied with the set parameters (power: 80 $\mathrm{mW}$, duration: $100 \mathrm{~ms}$; spot size: $100 \mu \mathrm{m})$.

\section{Hydrogen gas administration}

The mixed gas was produced by an AMS-H-01 hydrogen-oxygen nebulizer (Asclepius Medites Co., Shanghai, China), which contained $67 \% \mathrm{H}_{2}$ and $33 \% \mathrm{O}_{2}$ from water by electrolysis. Furthermore, $\mathrm{N}_{2}$ was applied to modulate the concentration of $\mathrm{O}_{2}$ at $21 \%$ equal with the conventional condition. Rats in the hydrogen gas $(\mathrm{H})$ group inhaled the gas mixture $\left(21 \% \mathrm{O}_{2}, 42 \% \mathrm{H}_{2}, 37 \% \mathrm{~N}_{2}\right)$ at $3 \mathrm{~L} / \mathrm{min}$ for $8 \mathrm{~h}$ (once/day, $30 \mathrm{~d}$ ). Additionally, the concentration of hydrogen gas was monitored by thermal trace GC ultra-gas chromatography (Thermo Fisher, MA, USA) and maintained at $42 \%$ concentration throughout the study. The rats were placed into a special closed gas chamber and moved freely. Rats in the model (M) group and the control $(\mathrm{C})$ group did not receive any treatment.

\section{Electroretinography}

FfERG measurement was performed as an international electrophysiological standard (ISCEV), including dark-adapted 0.01 response, dark-adapted 3.0 response, dark-adapted oscillatory potentials, light-adapted 3.0 response and light-adapted flicker response at $1,7,14$ and $30 \mathrm{~d}$ post-occlusion as previously described [17-19]. Briefly, rats were adapted in a dark environment for $12 \mathrm{~h}$ for dark adaptation. All operation procedures were performed in a dim, 
red-light room. Rats were anaesthetized as described above. The pupils were dilated with $0.5 \%$ tropicamide ahead of ERG operation. FfERG was recorded using full-field (Ganzfeld) stimulation with a computer system (RETI port; Roland Consult $\mathrm{GmbH}$, Brandenburg, Germany). The recording electrode was a custom-made silver chloride electrode placed softly on the centre of the cornea. Stainless steel needle electrodes were placed in the cheek and tail to serve as the reference and ground electrodes, respectively. Gatifloxacin eye gel (Shenyang Xingji Co., Ltd., Liaoning, China) was used three times a day after ERG testing to avoid infection.

\section{$\mathrm{OCT}$, fundus photograph and ear microcirculation detection}

OCT image detection was used on $1,7,14$ and $30 \mathrm{~d}$ post-occlusion. The detection procedure complied with the operator manual. The right eye had previously been dilated with $0.5 \%$ tropicamide. Then, gatifloxacin eye gel was used as coupling gel to protect the rat cornea from injury. Fundus and OCT images were captured from 20 positions for each eye using a Retinal Imaging System (OPTO-RIS, OptoProbe, Canada) and a 4D-ISOCT Microscope Imaging System (ISOCT, OptoProbe, Canada). The thickness of the retinal layers was calculated with OCT Image Analysis Software (OptoProbe, Version 2.0, Canada). Furthermore, BRVO rat model ear microcirculation was detected by a microcirculation detector (Xindi Co., Ltd., Shanghai, China).

\section{Immunofluorescence staining}

Immunofluorescence staining was performed according to the manufacturer's instructions at $1,7,14$ and $30 \mathrm{~d}$ post-occlusion $(n=3)$. Paraffin eye sections were deparaffinized in dimethylbenzene and dehydrated in gradient ethyl alcohol. Then, the sections were washed in phosphate buffer saline (PBS; 0.1 mM, pH 7.2) 3 times for 5 min. Antigen retrieval solution $(9 \mathrm{~mL} 0.1 \mathrm{mmol} / \mathrm{L}$ citric

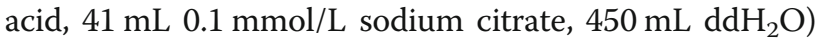
was performed with a medium baking temperature for 10 min. Next, the sections were washed in PBS 3 times for $5 \mathrm{~min}$. Then, $10 \%$ goat serum was applied for $2 \mathrm{~h}$, and the sections were incubated with anti-VEGF- $\alpha$ (\#GTX102643, Gene Tex, Irvine, CA) at a 1:100 dilution overnight at $4{ }^{\circ} \mathrm{C}$. Slides incubated without primary antibody served as control slides. The slides were washed with PBS 3 times for $5 \mathrm{~min}$ and incubated with $\mathrm{Cy} 3$ marked goat anti-rabbit IgG $(\mathrm{H}+\mathrm{L})$ fluorescence secondary antibody (Zhuangzhi, EK022, Xi'an, Shaanxi Province, China) at 1:200 dilution for $1 \mathrm{~h}$ at room temperature. Slides were again washed in PBS 3 times for $5 \mathrm{~min}$. DAPI $(100 \mathrm{ng} / \mathrm{mL})$ was used to stain nuclei for $10 \mathrm{~min}$. Images of the slides were captured on a fluorescence microscope (BX53, Olympus, Japan).

\section{Statistical analyses}

Analysis of variance (ANOVA) followed by Bonferroni's post hoc analysis was performed to examine the significant differences among all groups unless otherwise specified; the values were presented as the mean \pm standard deviation (SD), with $p \leq 0.05$ considered statistically significant.

\section{Results \\ BRVO rat model}

The BRVO model was confirmed by OCT and fundus photography. Twenty-four BRVO rats were constructed successfully, a success rate of $80 \%$ (24/30). Moreover, 24 BRVO rats were randomly divided into 2 groups: the hydrogen gas $(\mathrm{H})$ group $(n=12)$ and the model $(\mathrm{M})$ group $(n=12)$. Twelve age-matched male rats served as the control $(C)$ group.

\section{Effects of hydrogen gas on retinal function}

To evaluate the retinal function of BRVO treated with hydrogen gas, ffERG was performed. As shown in Fig. 1, the amplitudes of the b wave (dark adaptation 3.0 response) and the OPs2 wave in the $H$ group and the $M$ group were decreased compared with those in the $\mathrm{C}$ group at 1, 7 and $14 \mathrm{~d}$ post-occlusion (all $p<0.05$ ), while there were no significant differences among the $\mathrm{H}$ group, $\mathrm{M}$ group and $\mathrm{C}$ group at $30 \mathrm{~d}$ post-occlusion $(p>0.05)$. In addition, the rats in the $\mathrm{H}$ group had higher amplitudes of b wave and OPs2 wave compared with those in the $M$ group at $7 \mathrm{~d}$ post-occlusion (all $p<$ 0.05). Interestingly, the amplitudes of the light-adapted flicker response $(\mathrm{N}-\mathrm{P})$ in the $\mathrm{H}$ group and $\mathrm{M}$ group were all dramatically decreased compared with that of the $\mathrm{C}$ group at every detecting point (all $p<$ 0.05). Moreover, the amplitude of the light-adapted flicker response (N-P) in the $\mathrm{H}$ group was higher than that in the $\mathrm{M}$ group at $7 \mathrm{~d}$ post-occlusion $(p<$ 0.05), and there existed no significant difference between the $H$ group and the $M$ group at 1,14 and 30 $\mathrm{d}($ all $p>0.05)$.

\section{Effects of hydrogen gas on branch retinal vein recovery}

To explore the evolution process of the occlusive vein, fundus photographs were applied at 1, 3, 5, 7, 14 and 30 $\mathrm{d}$ after the BRVO model was established with laser photocoagulation. The obvious occlusive vein and non-perfusion were observed in both the $\mathrm{H}$ group and the $M$ group at $1 \mathrm{~d}$ post-occlusion. As shown in Fig. 2a, the reopen time in the $\mathrm{H}$ group was $2.235 \pm 1.128 \mathrm{~d}$, which was shorter than that in the $M$ group (4.234 \pm $2.236 \mathrm{~d}, p<0.05)$. 


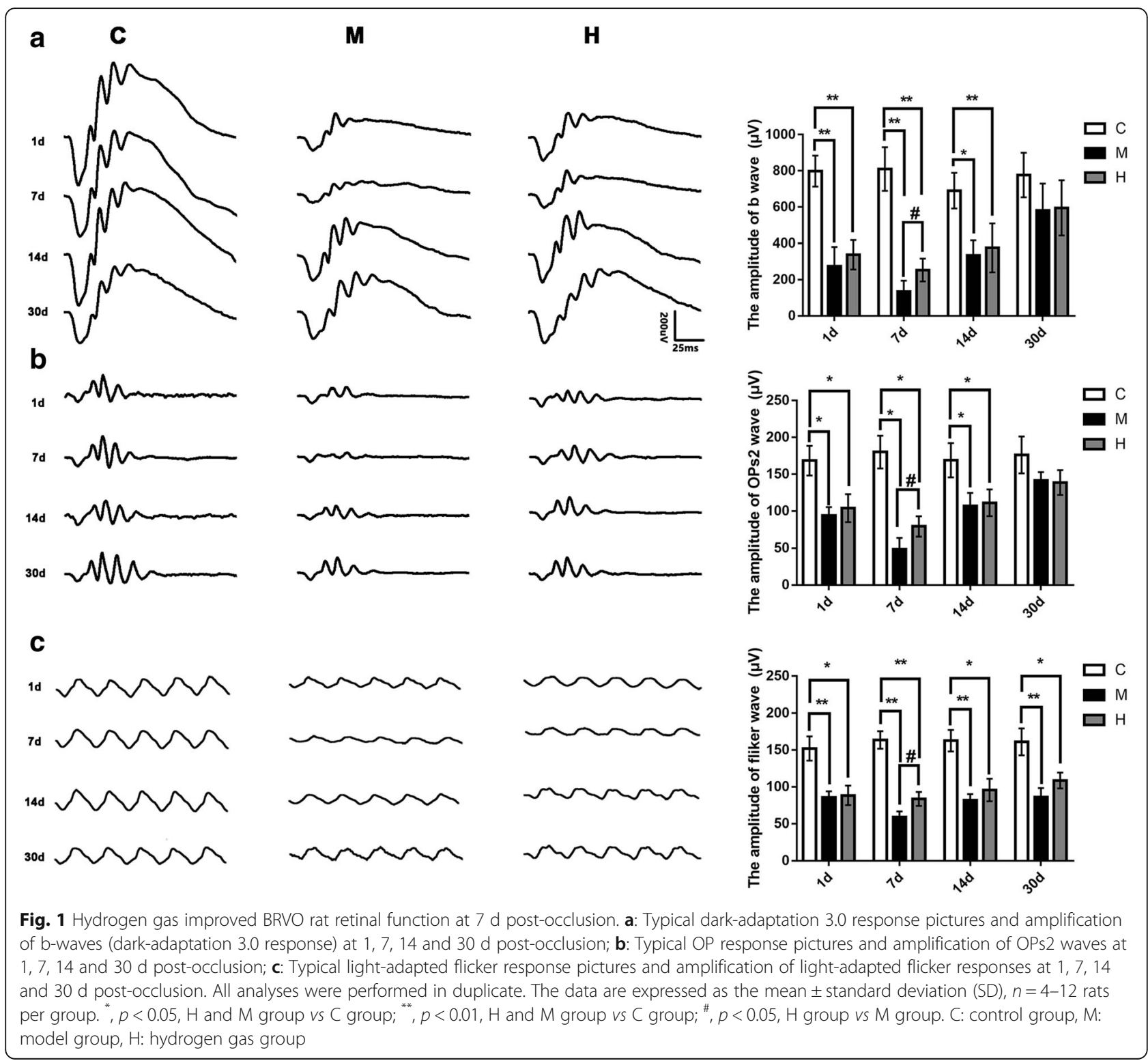

\section{Effects of hydrogen gas on retinal structure}

To evaluate the protective effect of hydrogen gas on retinal structure after BRVO in vivo, OCT was performed. For OCT, the low-reflective band contained the inner nuclear layer (INL) and outer nuclear layer (ONL), which were composed of nuclear. Moreover, the high-reflective band contained the inner plexiform layer (IPL), outer plexiform layer (OPL), photoreceptor inner segment/outer segment (IS/OS) junction line and retinal pigment epithelium (RPE) layer. As shown in Fig. 2b, OCT found that the thickness of the total retina in the BRVO area of the M group was remarkably increased for laser-induced oedema at $1 \mathrm{~d}$ but significantly decreased at 7, 14 and $30 \mathrm{~d}$ post-occlusion compared with that of the $\mathrm{C}$ group (all $p<0.05$ ). Furthermore, there were no significant differences between the $\mathrm{H}$ and $\mathrm{C}$ groups at $1 \mathrm{~d}$ post-occlusion $(p>0.05)$. At the same time, the thickness of the total retina was more oedematous in the $M$ group compared with that in the $\mathrm{H}$ group at $3 \mathrm{~d}$ post-occlusion $(p<0.05)$. Interestingly, we found that the total retina thickness in the $M$ group was dramatically decreased compared with that in the $\mathrm{H}$ group at $30 \mathrm{~d}$ post-occlusion $(p<0.05)$. Specifically, as shown in Fig. 2c and d, the thicknesses of the ONL and INL in the $\mathrm{H}$ group and $\mathrm{M}$ group were dramatically decreased compared with those in the $\mathrm{C}$ group at $3,5,7$, 14 and $30 \mathrm{~d}$ post-occlusion (all $p<0.05$ ). Moreover, it was found that the thickness of the INL in the $\mathrm{H}$ group was thicker than that in the M group at 7, 14 and $30 \mathrm{~d}$ post-occlusion (all $p<0.05$ ). As for the inner plexiform layer (IPL) + ganglion cell layer $(\mathrm{GCL})+$ nerve fibre layer (NFL), as shown in Fig. 2e, those in the $\mathrm{H}$ group and the 


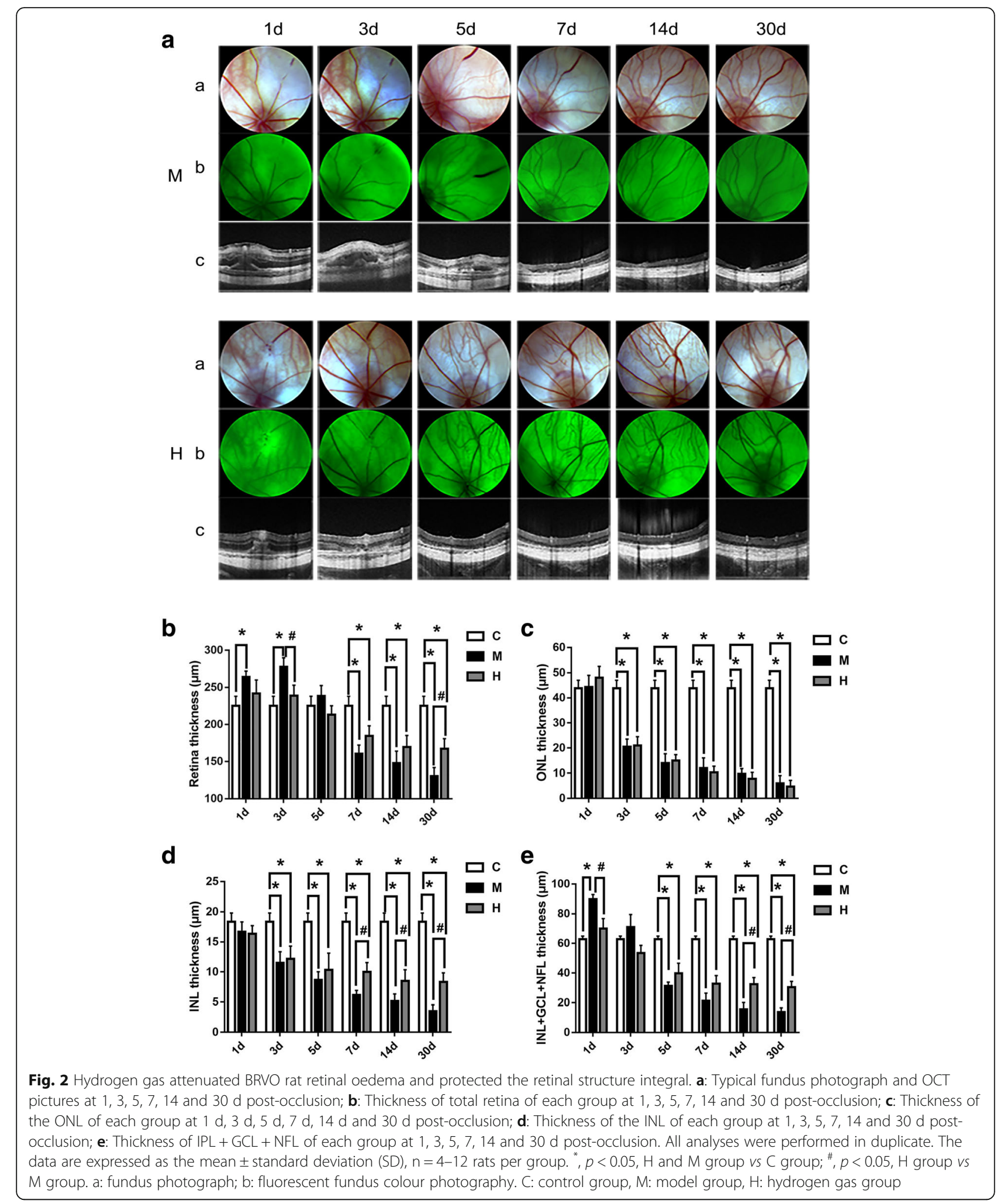

$\mathrm{M}$ group were reduced compared with those in the $\mathrm{C}$ group at 5, 7, 14 and $30 \mathrm{~d}$ post-occlusion (all $p<0.05$ ). The thickness of the IPL + GCL + NFL in the M group was severely oedematous compared with those in the
$\mathrm{C}$ group and the $\mathrm{H}$ group at $1 \mathrm{~d}$ post-occlusion (all $p<0.05$ ). At $14 \mathrm{~d}$ and $30 \mathrm{~d}$ post-occlusion, the thickness of the IPL + GCL + NFL in the H group was thicker than that in the M group (all $p<0.05$ ). 


\section{Effects of hydrogen gas on microcirculation}

Microcirculation was used to evaluate occlusive vein prognosis. The microcirculation detector found that the flow velocity of ear vein blood was decreased in the $M$ group compared with that in the $\mathrm{H}$ and $\mathrm{C}$ groups at $7 \mathrm{~d}$ post-occlusion (all $p<0.05$ ), while there was no significant difference between the $\mathrm{H}$ and $\mathrm{C}$ groups (all $p>0.05$ ) (Fig. 3).

\section{Effects of hydrogen gas on the expression of retina VEGF-}

\section{a}

To evaluate the expression of VEGF- $\alpha$ treated or untreated with hydrogen gas, immunofluorescence was applied. As shown in Fig. 4, VEGF- $\alpha$ was expressed mainly in the ganglion cell layer (GCL). Furthermore, the expression of VEGF- $\alpha$ in the $H$ and $M$ groups at $1 \mathrm{~d}$ post-occlusion was dramatically increased compared with that in the $\mathrm{C}$ group (all $p<0.05$ ), while the expression of VEGF- $\alpha$ in the $H$ group was less than that in the $\mathrm{M}$ group $(p<0.05)$. At 1,7 and $14 \mathrm{~d}$ post-occlusion, the expression of VEGF- $\alpha$ in the $H$ group was significantly lower than that in the $\mathrm{M}$ group (all $p<0.05$ ). However, there were no significant differences among the groups at $30 \mathrm{~d}$ post-occlusion (all $p>0.05$ ).

\section{Discussion}

In this study, hydrogen gas via inhalation administration could protect BRVO rat retinal function recovery and retina structural integrity. We found that hydrogen gas could shorten the reopen time and improve ear vein microcirculation. Interestingly, hydrogen gas could lighten retinal oedema induced by BRVO at the early stage and prevent the retina from becoming thinner. More importantly, hydrogen gas could decrease the expression of VEGF- $\alpha$ to improve hypoxia in the early time of post-occlusion.

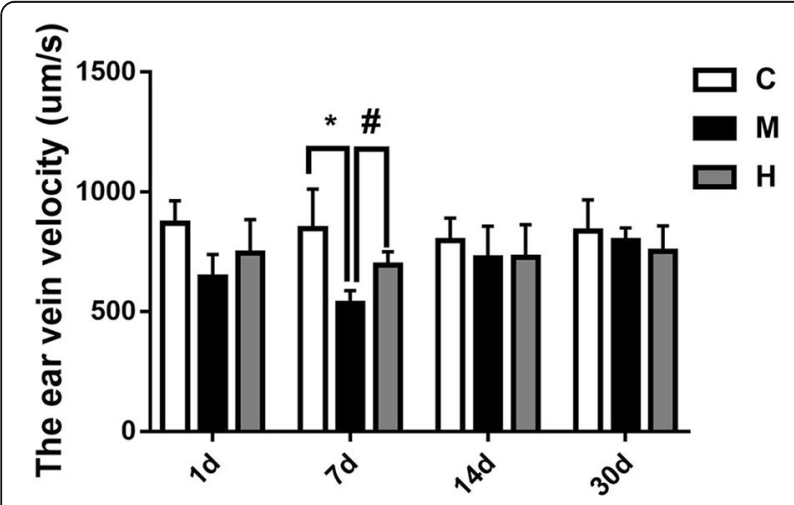

Fig. 3 Hydrogen gas improved BRVO rat microcirculation at $7 \mathrm{~d}$ post-occlusion. BRVO rats ear vein blood flow velocity at 1, 7, 14 and $30 \mathrm{~d}$. All analyses were performed in duplicate. The data are expressed as the mean \pm standard deviation (SD), $n=4-12$ rats per group. ${ }^{*}, p<0.05, \mathrm{H}$ and M group vs C group; ${ }^{*}, p<0.05, \mathrm{H}$ group vs M group. C: control group, $\mathrm{M}$ : model group, $\mathrm{H}$ : hydrogen gas group
BRVO is one of the most common vessel-associated ophthalmology diseases and damages sight to different degrees [20]. It has been difficult for people to manage and treat BRVO itself due to its problematic complications. An essential reason is the lack of a suitable BRVO animal model. In the literature, people established the BRVO model by laser photocoagulation [21], diathermic cauterization, intravitreal injection of PD032590 [22], thrombin [23], NPe6 [24], or endothelin-1(ET-1) [25]. We have previously shown that modified laser photocoagulation could superbly mimic BRVO disease. In this study, the BRVO rat model was established by a modified laser photocoagulation method, which featured stabilization and homogeneity. The typical features of BRVO, such as retinal oedema, non-perfusion and reperfusion, were observed in the experiment. Retinal oedema was observed mainly at the inner retinal layer around the occlusive site at the early stage $(1 \mathrm{~d}$ to $3 \mathrm{~d}$ post-occlusion). We found that retinal oedema mainly existed in the IGL, the GCL and the NFL, which was in accordance with the previous study [26]. Additionally, retinal atrophy and photoreceptor cell loss (the ONL almost disappeared) were observed at 14 and $30 \mathrm{~d}$ post-occlusion, which would be related to BRVO complication retinal oedema [27].

Hydrogen gas has received increasing attention in many disorders since Ohsawa demonstrated that it could remarkably suppress I/R brain injury by buffering the effects of oxidative stress. Moreover, hydrogen gas could activate the NF-E2-related factor 2 (Nrf2) cell signal pathway [13], which reduced OS by upregulating a variety of antioxidant enzymes [28]. However, the specific mechanisms of hydrogen gas have not been completely illustrated, which is urgent for further explanation. Many studies have clarified and confirmed the varying degrees of the effect of hydrogen gas, and the potential advantages have been reported: 1) hydrogen gas could rapidly diffuse across cell membranes and directly target and eliminate intracellular reactive oxygen species (ROS), such as hydroxide radical $(\bullet \mathrm{OH})$ and peroxynitrite $(\mathrm{ONOO} \bullet)$; 2) hydrogen gas is a mild deoxidizer, which has little effect on the normal ROS-associated cell signal pathway [29]; and 3) hydrogen gas is obtained easily and is safe even at high concentrations [30, 31]. Considering the specific effect, hydrogen gas could easily pass through the phospholipid bilayer and be administered in BRVO to eliminate free radicals as a promising treatment.

An accurate description of the BRVO mechanism has not been totally clear. Studies have found that VEGF- $\alpha$ played a key role in BRVO prognosis and development [32] because it is tightly associated with BRVO complications, such as fragile neovascularization, haemorrhage and retinal oedema. Therefore, agents that target at VEGF- $\alpha$ have been regarded as a promising method. At 
a
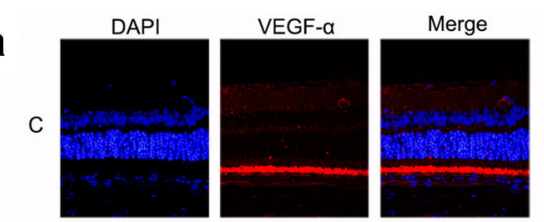

M
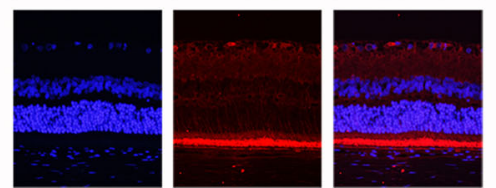

$\mathrm{H}$
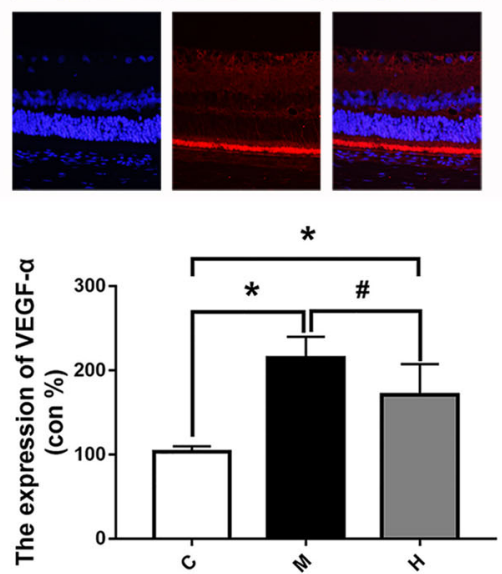

C
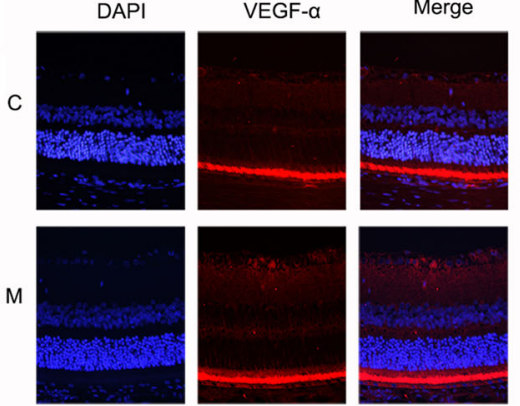

$\mathrm{H}$
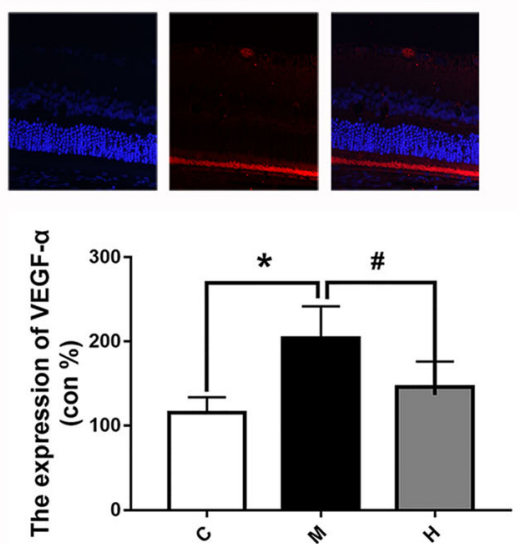

b
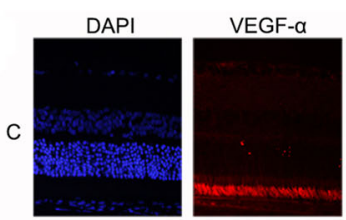

Merge
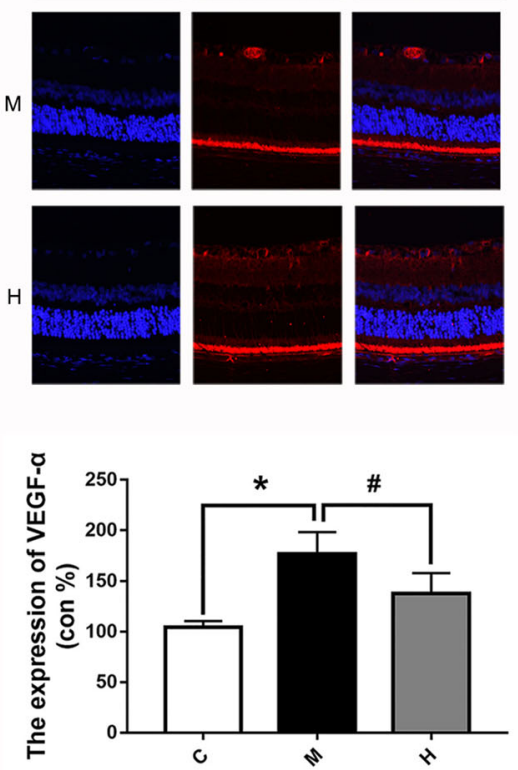

d
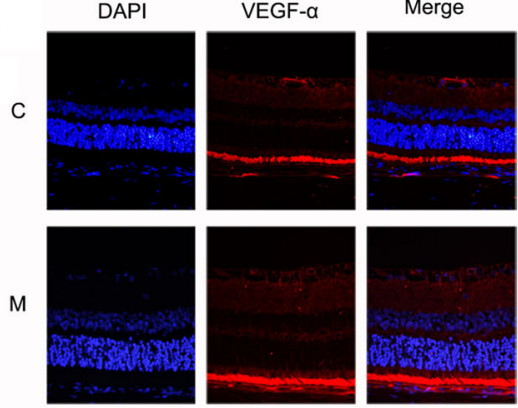

$\mathrm{H}$
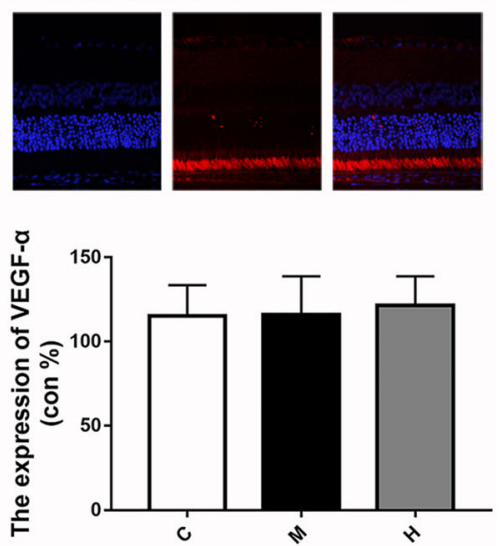

Fig. 4 Hydrogen gas decreased the expression of VEGF-a at 1, 7 and 14 d post-occlusion. a: Typical immunofluorescence staining picture and expression of VEGF-a at $1 \mathrm{~d}$ post-occlusion. $\mathbf{b}$ : Typical immunofluorescence staining picture and expression of VEGF-a at $7 \mathrm{~d}$ post-occlusion. $\mathbf{c}$ : Typical immunofluorescence staining picture and expression of VEGF-a at $14 \mathrm{~d}$ post-occlusion. $\mathbf{d}$ : Typical immunofluorescence staining picture and expression of VEGF-a at $30 \mathrm{~d}$ post-occlusion. All analyses were performed in duplicate. The data are expressed as the mean \pm standard deviation (SD), $\mathrm{n}=3$ rats per group. ${ }^{*}, p<0.05, \mathrm{H}$ and $\mathrm{M}$ group vs $\mathrm{C}$ group; ${ }^{\#}, p<0.05, \mathrm{H}$ group vs M group. C: control group, M: model group, H: hydrogen gas group 
present, anti-VEGF- $\alpha$ is a direct intervention to reduce the expression of VEGF- $\alpha$, and clinical studies have confirmed that it is valid [33, 34]. However, anti-VEGF- $\alpha$ agents still inevitably exhibit some potential disadvantages: 1) molecular targeting drugs are expensive for BRVO patients from poor countries; 2) some patients are insensitive to anti-VEGF- $\alpha$ agents and even suffer severe side effects [10, 35]; and 3) VEGF- $\alpha$ plays an essential role in physical reactions, and anti-VEGF- $\alpha$ agents would influence retinal nerve cells [36-38]. It is known that excessive generation of VEGF- $\alpha$ is accompanied by histiocyte hypoxia, which is associated with further vascular leakage and retinal oedema [39]. However, we could not ignore the physical role of VEGF- $\alpha$, which was indispensable for retina self-repair. In our study, we found that hydrogen gas inhalation could effectively decrease the expression of VEGF- $\alpha$ in the early BRVO stage and shorten BRVO reopen time by indirectly regulating VEGF- $\alpha$. Therefore, we hypothesized that hydrogen gas could improve ischaemia reperfusion injury and could be applied to those who were insensitive to anti-VEGF- $\alpha$ treatment and covered with severe adverse effects. Moreover, compared with anti-VEGF- $\alpha$ agents, hydrogen gas could directly improve retinal hypoxia conditions, and the potential mechanisms could be related to selectively eliminating strong free radicals, inhibiting inflammatory factors and active cell survival signals [40]. In the future, we would like to explore the specific mechanisms of hydrogen gas on BRVO treatment.

Interestingly, we found that ERG function, microcirculation and the expression of VEGF- $\alpha$ were not significantly different in the $\mathrm{H}$ group compared with the $\mathrm{M}$ group at $30 \mathrm{~d}$ post-occlusion. However, we could recognize the obvious retina structural differences between the $\mathrm{H}$ group and the $\mathrm{M}$ group at $30 \mathrm{~d}$ post-occlusion. Moreover, we found that hydrogen gas could promote occlusive vein reopening. Meanwhile, ERG showed that hydrogen gas could reduce the rapid declines of the b-wave (dark-adaptation 3.0 response), OPs2 response and light-adapted flicker response at $7 \mathrm{~d}$ post-occlusion when the fundus photograph found it was close to the BRVO reopen time. We speculated that hydrogen gas could alleviate retina ischaemia-reperfusion injury, which protected retina structural integrity.

\section{Conclusion}

The study showed that hydrogen gas played a specific role in alleviating retinal oedema, improving retinal microcirculation, protecting visual function and regulating VEGF- $\alpha$ expression. Taken together, the study provided curative support that hydrogen gas was beneficial for clinical application on BRVO disorder as an adjuvant treatment.

\section{Abbreviations}

ARVO: Association for Research in Vision and Ophthalmology; BRVO: Branch retinal vein occlusion; CRVO: Central retinal vein occlusion; d3.0: darkadaptation 3.0 response; ffERG: full-field electroretinography; Nrf2: NF-E2related factor 2; OPs2: Oscillatory potentials; OS: Oxidative stress;

ROS: Reactive oxygen species; SD: Sprague-Dawley

\section{Acknowledgements}

The authors thank Professor Yusheng Wang for helping establish a rat model from the Department of Ophthalmology of Xijing Hospital, Fourth Military Medical University. Moreover, the authors thank Professor Jiancong Wang for helping perform OCT devices from BeiJing HealthOLight technology Co., Ltd.

\section{Funding}

This work was supported by the National Nature Science Foundation of China (81500724) and the Shaanxi Province Programs for Social

Development of Science and Technology (2016SF-063). The funder had no role in the study design, data collection and analysis, decision to publish or preparation of the manuscript.

\section{Availability of data and materials}

The datasets used and analysed in the present study are available from the corresponding author on reasonable request.

\section{Authors' contributions}

JA, TC and ZMZ designed the experiments. PL and WMY conducted the experiments, analysed the data and wrote the manuscript. MSH, ZW and QLZ provided intellectual support and edited the manuscript. MHL and JHX revised the manuscript. All authors read and approved the final manuscript.

\section{Ethics approval and consent to participate}

The study was approved by the Ethical Committee of the Animal Care and Experimental Committee of Fouth Military Medical University, and the procedures conformed to the statements of the ARVO Statement for the Use of Animals in Ophthalmic and Vision Research.

\section{Consent for publication \\ Not applicable.}

\section{Competing interests}

The authors declare that they have no competing interests.

\section{Publisher's Note}

Springer Nature remains neutral with regard to jurisdictional claims in published maps and institutional affiliations.

\section{Author details}

${ }^{1}$ Center of Clinical Aerospace Medicine, Fourth Military Medical University, No.169 Changle West Road, Xi'an 710032, Shaanxi, China. ${ }^{2}$ Department of Ophthalmology, The 900th Hospital of the Joint Logistics Team of Chinese PLA, Fuzhou 350025, Fujian, China. ${ }^{3}$ Department of Chinese Material Medical and Natural Medicines, Fourth Military Medical University, Xi'an 710032, Shaanxi, China. ${ }^{4}$ Company 11 Brigade 4, College of Basic Medicine, Fourth Military Medical University, Xi'an 710032, Shaanxi, China. ${ }^{5}$ Department of Ophthalmology of Xijing Hospital, Fourth Military Medical University, Xi'an 710032, Shaanxi, China. ${ }^{6}$ Institute of Neurobiology, School of Basic Medical Sciences, Xi'an Jiaotong University, No.76 Yanta Weast Road, Xi'an 710061, Shaanxi, China.

Received: 31 December 2018 Accepted: 10 April 2019 Published online: 16 May 2019

\section{References}

1. Thapa R, Bajimaya S, Paudyal G, Khanal S, Tan S, et al. Prevalence, pattern and risk factors of retinal vein occlusion in an elderly population in Nepal: the Bhaktapur retina study. BMC Ophthalmol. 2017;17:162.

2. Cheung N, Klein R, Wang JJ, Cotch MF, Islam AF, et al. Traditional and novel cardiovascular risk factors for retinal vein occlusion: the multiethnic study of atherosclerosis. Invest Ophthalmol Vis Sci. 2008;49:4297-302. 
3. Ponto KA, Elbaz H, Peto $T$, Laubert-Reh D, Binder $H$, et al. Prevalence and risk factors of retinal vein occlusion: the Gutenberg health study. J Thromb Haemost. 2015;13:1254-63.

4. Adelman RA, Parnes AJ, Bopp S, Saad OI, Ducournau D. Strategy for the management of macular edema in retinal vein occlusion: the European VitreoRetinal society macular edema study. Biomed Res Int. 2015;2015: 870987

5. Mitry, D., Bunce, C., Charteris, D. (2013) Anti-vascular endothelial growth factor for macular oedema secondary to branch retinal vein occlusion. Cochrane Database Syst RevD9510.

6. Demir M, Oba E, Guven D, Acar Z, Cinar S. Results of intravitreal triamcinolone acetonide in patients with macular edema secondary to branch retinal vein occlusion. Int J Clin Pharm. 2014:36:438-42.

7. Blanc J, Deschasse C, Kodjikian L, Dot C, Bron AM, et al. Safety and longterm efficacy of repeated dexamethasone intravitreal implants for the treatment of cystoid macular edema secondary to retinal vein occlusion with or without a switch to anti-VEGF agents: a 3-year experience. Graefes Arch Clin Exp Ophthalmol. 2018;256:1441-8.

8. Campochiaro, P. A., Sophie, R., Pearlman, J., Brown, D. M., Boyer, D. S. et al. (2014) Long-term outcomes in patients with retinal vein occlusion treated with ranibizumab: the RETAIN study. Ophthalmology. 121, 209-219.

9. Konidaris VE, Tsaousis KT, Anzidei R, de la Mata G, Brent AJ. Real-world results of switching treatment from Ranibizumab to Aflibercept in macular Oedema secondary to branch retinal vein occlusion. Ophthalmol Ther. 2018; 7:387-95.

10. Yang CS, Liu JH, Chung YC, Chou YB, Hung KH. Combination therapy with intravitreal bevacizumab and macular grid and scatter laser photocoagulation in patients with macular edema secondary to branch retinal vein occlusion. J Ocul Pharmacol Ther. 2015;31:179-85.

11. Hsueh J, Wai KM, Conti FF, Conti TF, Singh RP. Impact of time to antivascular endothelial growth factor intervention on visual outcomes for patients diagnosed with retinal vein occlusion. Ophthalmic Surg Lasers Imaging Retina. 2018;49:832-7.

12. Ehlken, C., Helms, M., Bohringer, D., Agostini, H. T., Stahl, A. (2018) Association of treatment adherence with real-life VA outcomes in AMD, DME, and BRVO patients. Clin Ophthalmol 12, 13-20.

13. Ohta S. Molecular hydrogen as a preventive and therapeutic medical gas: initiation, development and potential of hydrogen medicine. Pharmacol Ther. 2014;144:1-11.

14. Qi, L. S., Yao, L., Liu, W., Duan, W. X., Wang, B. et al. (2015) Sirtuin type 1 mediates the retinal protective effect of hydrogen-rich saline against lightinduced damage in rats. Invest Ophthalmol Vis Sci 56, 8268-8279.

15. Yan WM, Chen T, Wang XC, Qi LS, Zhao GH, et al. The reason for the amelioration of $\mathrm{N}$-methyl-N-nitrosourea-induced retinitis pigmentosa in rats by hydrogen-rich saline. Int J Ophthalmol. 2017;10:1495-503.

16. Yan, W. M., Zhang, L., Chen, T., Zhao, G. H., Long, P. et al. (2017) Effects of hydrogen-rich saline on endotoxin-induced uveitis. Med Gas Res 7, 9-18.

17. McCulloch DL, Marmor MF, Brigell MG, Hamilton R, Holder GE, et al. ISCEV standard for full-field clinical electroretinography (2015 update). Doc Ophthalmol. 2015;130:1-12.

18. Long P, Yan W, Liu J, Li M, Chen T, et al. Therapeutic effect of traditional Chinese medicine on a rat model of branch retinal vein occlusion. J Ophthalmol. 2019:2019:1-13.

19. He M, Long P, Yan W, Chen T, Guo L, et al. ALDH2 attenuates early-stage STZ-induced aged diabetic rats retinas damage via Sirt1/Nrf2 pathway. Life Sci. 2018;215:227-35.

20. Jonas JB, Xu L, Wang YX. The Beijing eye study. Acta Ophthalmol. 2009;87: 247-61.

21. Ham DI, Chang K, Chung H. Preretinal neovascularization induced by experimental retinal vein occlusion in albino rats. Korean J Ophthalmol. 1997;11:60-4.

22. Huang W, Yang AH, Matsumoto D, Collette W, Marroquin $L$, et al. PD0325901, a mitogen-activated protein kinase kinase inhibitor, produces ocular toxicity in a rabbit animal model of retinal vein occlusion. J Ocul Pharmacol Ther. 2009;25:519-30.

23. Tamura M. Neovascularization in experimental retinal venous obstruction in rabbits. Jpn J Ophthalmol. 2001;45:144-50.

24. El-Dessouky, E. S., Moshfeghi, A. A., Peyman, G. A., Yoneya, S., Mori, K. et al. (2001) Toxicity of the photosensitizer NPe6 following intravitreal injection. Ophthalmic Surg Lasers 32, 316-321.
25. Takei K, Sato T, Nonoyama T, Miyauchi T, Goto K, et al. A new model of transient complete obstruction of retinal vessels induced by endothelin-1 injection into the posterior vitreous body in rabbits. Graefes Arch Clin Exp Ophthalmol. 1993:231:476-81.

26. Wallow IH, Danis RP, Bindley C, Neider M. Cystoid macular degeneration in experimental branch retinal vein occlusion. Ophthalmology. 1988;95:1371-9.

27. leki Y, Nishiwaki H, Miura S, Yamashiro K, Nishijima K, et al. Experimental macular edema induced by macular venule occlusion in monkey. Curr Eye Res. 2002;25:123-31.

28. Johnson DA, Johnson JA. Nrf2--a therapeutic target for the treatment of neurodegenerative diseases. Free Radic Biol Med. 2015;88:253-67.

29. Sauer $H$, Wartenberg $M$, Hescheler J. Reactive oxygen species as intracellular messengers during cell growth and differentiation. Cell Physiol Biochem. 2001;11:173-86.

30. Ohta S. Recent progress toward hydrogen medicine: potential of molecular hydrogen for preventive and therapeutic applications. Curr Pharm Des. 2011;17:2241-52.

31. Fontanari $\mathrm{P}$, Badier M, Guillot C, Tomei C, Burnet $H$, et al. Changes in maximal performance of inspiratory and skeletal muscles during and after the 7.1-MPa Hydra 10 record human dive. Eur J Appl Physiol. 2000;81:325-8.

32. Yao J, Chen Z, Yang Q, Liu X, Chen X, et al. Proteomic analysis of aqueous humor from patients with branch retinal vein occlusion-induced macular edema. Int J Mol Med. 2013;32:1421-34

33. Kida T, Flammer J, Oku H, Morishita S, Fukumoto M, et al. Suppressed endothelin-1 by anti-VEGF therapy is important for patients with BRVOrelated macular edema to improve their vision. EPMA J. 2016;7:18.

34. Campochiaro PA, Heier JS, Feiner L, Gray S, Saroj N, et al. Ranibizumab for macular edema following branch retinal vein occlusion: six-month primary end point results of a phase III study. Ophthalmology. 2010;117:1102-12.

35. Pielen A, Feltgen N, Isserstedt C, Callizo J, Junker B, et al. Efficacy and safety of intravitreal therapy in macular edema due to branch and central retinal vein occlusion: a systematic review. PLoS One. 2013;8:e78538.

36. Huang ZL, Lin KH, Lee YC, Sheu MM, Tsai RK. Acute vision loss after intravitreal injection of bevacizumab (avastin) associated with ocular ischemic syndrome. Ophthalmologica. 2010;224:86-9.

37. Vertes D, Snyers B, De Potter P. Cytomegalovirus retinitis after low-dose intravitreous triamcinolone acetonide in an immunocompetent patient: a warning for the widespread use of intravitreous corticosteroids. Int Ophthalmol. 2010;30:595-7.

38. Romero-Aroca P. Current status in diabetic macular edema treatments. World J Diabetes. 2013:4:165-9.

39. Campa C, Alivernini G, Bolletta E, Parodi MB, Perri P. Anti-VEGF therapy for retinal vein occlusions. Curr Drug Targets. 2016;17:328-36.

40. Wu J, Wang R, Yang D, Tang W, Chen Z, et al. Hydrogen postconditioning promotes survival of rat retinal ganglion cells against ischemia/reperfusion injury through the PI3K/Akt pathway. Biochem Biophys Res Commun. 2018; 495:2462-8
Ready to submit your research? Choose BMC and benefit from:
- fast, convenient online submission
- thorough peer review by experienced researchers in your field
- rapid publication on acceptance
- support for research data, including large and complex data types
- gold Open Access which fosters wider collaboration and increased citations
- maximum visibility for your research: over $100 \mathrm{M}$ website views per year
At $\mathrm{BMC}$, research is always in progress. 